\title{
Experimental simplified rule of self tuning fuzzy logic-model reference adaptive speed controller for induction motor drive
}

\author{
M.Z. Ismail, M.H.N. Talib, Z. Ibrahim, J. Mat Lazi, Z. Rasin
}

Faculty of Electrical Engineering, Universiti Teknikal Malaysia Melaka, Malaysia

\begin{tabular}{|c|c|}
\hline Article Info & ABSTRACT \\
\hline Article history: & \multirow{8}{*}{$\begin{array}{l}\text { Fuzzy logic controller (FLC) has shown excellent performance in dealing } \\
\text { with the non-linearity and complex dynamic model of the induction motor. } \\
\text { However, a conventional constant parameter FLC (CPFL) will not be able to } \\
\text { provide-good coverage performance for a wide speed range operation with a } \\
\text { single tuning parameter. Therefore, this paper proposed a self tuning } \\
\text { mechanism FLC approach by model reference adaptive controller (ST- } \\
\text { MRAC) to continuously allow to adjust the parameters. Due to real time } \\
\text { hardware application, the dominant rules selection method for simplified } \\
\text { rules has been implemented as part of the reducing computational burden. } \\
\text { Experiment results validate a good performance of the ST-MRAC compared } \\
\text { to the CPFL for the speed performance in terms of the wide range of } \\
\text { operations and disturbance showed remarkable performance. }\end{array}$} \\
\hline Received Feb 2, 2020 & \\
\hline Revised May 4, 2020 & \\
\hline Accepted May 25, 2020 & \\
\hline Keywords: & \\
\hline Fuzzy Logic & \\
\hline Fuzzy Logic Controller & \\
\hline $\begin{array}{l}\text { Model Reference Adaptive } \\
\text { Controller }\end{array}$ & \\
\hline
\end{tabular}

Corresponding Author:

Faculty of Electrical Engineering, Universiti Teknikal Malaysia Melaka, Durian Tunggal 76100, Malaysia.

Email: m_zamani_ismail@yahoo.com

\section{INTRODUCTION}

Two types of AC and DC electric motors have been introduced since the 1930s. The advantages of the AC motor are simple structure, low environmental dependence and easier to maintenance compared to the DC motor [1]. AC motors are generally is induction motor (IM), which are used routinely used in various fields such as agriculture, transport, manufacturing and other daily life [2]. With the high development of power electronics and microelectronics technology, more advanced control strategies can be used. For the high-performance drive system, the vector control technique provides excellent dynamic response and good controllability for IM drive. Besides, it offers a simple design and implementation [3]. By providing decoupling of torque and flux control demands, vector control can execute an AC similar to a separately DC motor drive. It operates without sacrificing the quality of dynamic performance [4].

The speed controller plays an important role in the performance of the IMs drive. Conventional speed controllers in IMs drive system have been controlled by proportional integral (PI) and proportional integral derivative (PID) for a long time ago. Several researchers claim this controller has simple structures, low computation, and satisfactory performance for a wide range of operating conditions [5, 6]. However, this controller is very much influence by the plant parameters and may difficult to get the right tuning values [7-9]. This is due to the limited ability to handle the non-linearities behaviour and complex dynamic model, especially when dealing with the three phase induction motor [10, 11]. Fuzzy logic controller (FLC) was proposed as an alternative and become a successful solution to the IM drive [12,13]. Over the last few decades, FLC has received great attention for IM drive application because to its robustness, less parameter sensitivity and performance improvement compared to the conventional PI controller [10, 14].

FLC is a heuristic control method that will be able to embed the key elements of human knowledge in designing a nonlinear controller. The crisps speed error signal will become the inputs signal converted into 
a fuzzy set. Three main parameters groups such as scaling factors, membership function and fuzzy rules are tuned and will effectively reduce the error and achieve the optimum performance [15]. However, for the constant parameters FL CPFL, the optimum performance can be achieved at the rated design operation only. Yet, when difference speed demand or disturbance existed, its performance will be degraded [16].

The self tuning mechanism has been introduced to address these issues. Fuzzy parameters are continuously tuned to adapt with any changes or disturbances occurred [17, 18]. The tuning parameters such as rules, membership functions (MF) and scaling factors (SF) can be tuned in a self-tuning fuzzy controller [19-21]. In the drive field, there are various Self-tuning FLC configurations and design structure. Self-tuning proposed in [12] is the simpler self-tuning method. This method only operates through the FLC tuner to update the output scaling factor of the main FLC. In overall, 49 x 2 number of fuzzy rules are used to determine the decision of the main controller and the output SF controller [13]. This research has been continued by [22], which covers on the different number of rules. As conclusion, the different size of the rules directly affects drive performance. By increasing the size of the fuzzy rules, the accuracy of the output results increases [23]. However, it will cause difficulties in realizing real-time implementation.

Efforts to realize self-tuning in real-time implementation has been continuously invented. The simplification rule method is one of the popular techniques that have been proposed in order to reduce computational requirements FLC. As a result, this technique reduces the number of fuzzy rules with minimum effect for fuzzy variables coverage and output decisions [22-24]. Another technique to reduce computerize burden to realize self-tuning in real-time implementation by using a different type of fuzzy from Mamdani to Takagi Sugeno (TS) [25]. The main characteristic of the TS is that singleton output MFs. A different method of self-tuning TS fuzzy type was proposed in [14] with model reference adaptive controller (MRAC) approach. The method was being tested by simulation and experimental setup; the outstanding results of this proposed method provide online tuning for all SF inputs and outputs.

This paper proposes simplified Mamdani self-tuning FLC with MRAC approach (ST-MRAC) for speed control induction motor drive. The proposed methods implement two FLC controllers with only 7 fuzzy rules for the main output control and 7 rules for the tuning mechanism through the simplification method's results. The output SF gain tuning mechanism is able to tune the value of change of error and output scaling factor simultaneously. In overall, only 14 numbers of rules are used for the proposed controller to reduce the computational burden for real-time implementation significantly. The overall drive system performances are compared between ST-MRAC and constant parameter FLC based on simulation and hardware for the variation of speed and load disturbance operations.

This paper is divided into five sections as follows: section 2 gives an overview of IM drive system. Section 3 describes the speed controller modeling. Evaluate the comparison of the results between STFL and the ST- MRAC in section 4. Finally, in section 5 summarize the findings and conclusions.

\section{FIELD ORIENTED CONTROL FOR INDUCTION MOTOR DRIVE}

Field Oriented Control (FOC) system is one of the most commonly controlled strategies used in high performance IM drive due to its robustness and high-performance [26]. The structure of the indirect field-oriented control (FOC) fed hysteresis current control (HCC) is shown in Figure 1. The AC motor drive can be performed likes a separately excited DC motor in vector control with the aid of feedback controllers [27]. The three-phase motor equations are transformed into a two-component coordinate system (dq axis) through Park or Clarke transformation [28-30]. It can be controlled separately the flux and torque as a DC motor. The mathematical model of the IM follows the discussion in [20, 31]. The electromagnetic torque is identical to the DC motor expression and can be interpreted as below when ids is zero.

$$
T e=\frac{3}{2} \frac{P}{2} \frac{L m}{L r}(\Psi d r I q s)
$$

Refer the model in Figure 1, just torque $\mathrm{q}$ component is controlled, while flux $\mathrm{d}$ component is constant value isq $*=2.9 \mathrm{~A}$ according to the datasheet of IM. Through inverse Park and Clarke transformation, the components of the current transform from isq * and isd * to iabc * respectively. HCC works as a switching signal generator for inverter by different current demands (iabc*)and actual current $(i a b c)$. HCC is used to control the inverter output voltage because of its simple and fast response characteristics $[32,33]$. Lastly, the inverter provides a voltage demand for IM. 


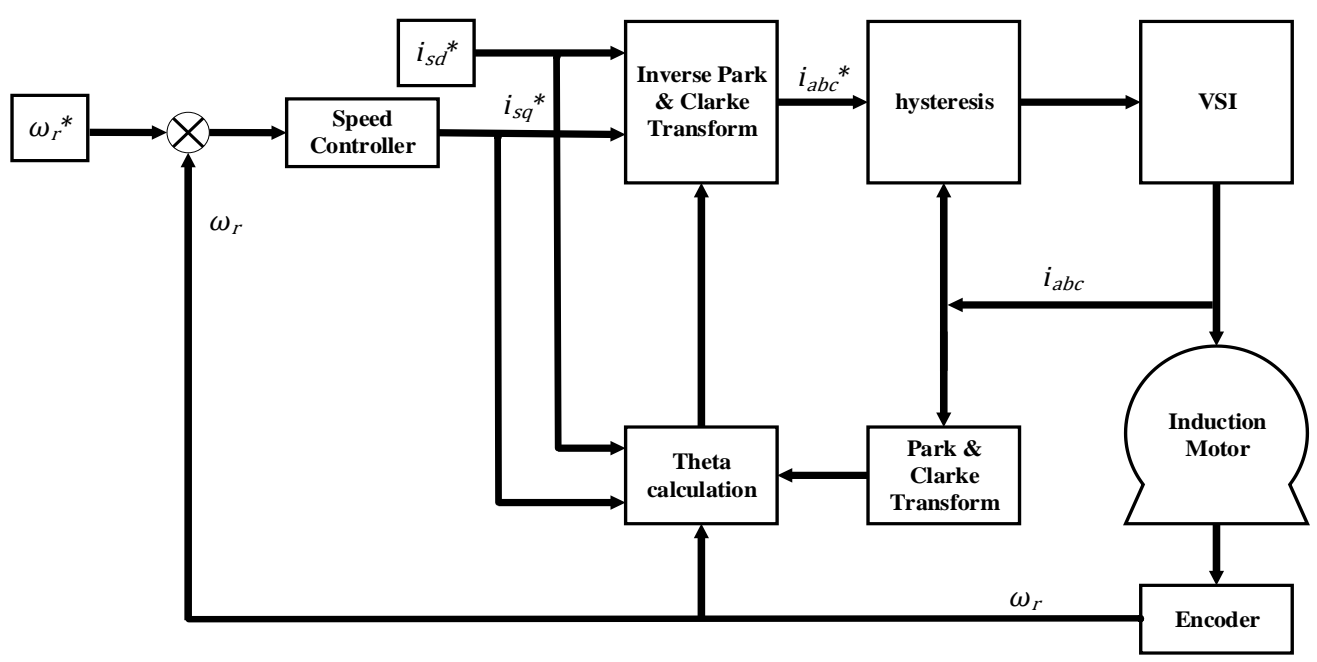

Figure 1. IFOC system fed by HCC

\section{FUZZY LOGIC SPEED CONTROLLER DESIGN}

Figure 2 shows an internal structure FLSC with one time tuning parameters or constant parameter (CPFL). The internal structure of FLC is divided into three parts: Pre-processing, Fuzzy logic and Postprocessing. The normalized input is processed in Pre-processing parts. Here, inputs SF gain value-speed error, Ge and change of speed error, Gce are determined as the (1) and (2) accordingly [34]. Where wemax and $\Delta \omega$ cemax with coefficient 2 is the maximum error and change of error for the rated speed to cover-up forward to reverse operations. The membership function and rule of fuzzy are designed in the second part. Range -2 to 2 MF error is designed to cover wider speed operation [24], while the MF change of error and output are designed in range -1 to 1 . A combination between the trapezoid and triangular shapes with $50 \%$ overlap is used to design the MF[12] as shown in Figure 3 for error (e) and Figure 4 for change of error (ce) and output (cu). The $5 \times 5 \mathrm{MF}$ was designed and labeled as Negative Big (NB), Negative Small (NS), Zero (ZE), Positive Small (PS) and Positive Big (PB). The relationship rules between error, change of error and output are states in Table 1, all the rules and MF design processes via knowledge-based experience, phase plane method [35, 36].

$$
\begin{aligned}
& G e=\frac{1}{|2 \omega \mathrm{emax}|} \\
& G c e=\frac{1}{|2 \Delta \omega \mathrm{emax}|}
\end{aligned}
$$

Table 1. Rules of FLSC

\begin{tabular}{cccccc}
\hline NB & NB & NS & ZE & PS & PB \\
NS & NB & NS & NS & NS & Z \\
ZE & NS & NS & Z & PS & PS \\
PS & NS & Z & PS & PS & PB \\
PB & Z & PS & PS & PB & PB \\
\hline & Simplified Rules & & & \\
* Note : & \multicolumn{2}{c}{ Sim } & & &
\end{tabular}

The output torque current, Iq* compute by the center of gravity (COG) technique. The denormalized output is operated in the last part, which is Post-processing and the output SF factor, Gcu set as 1 . 


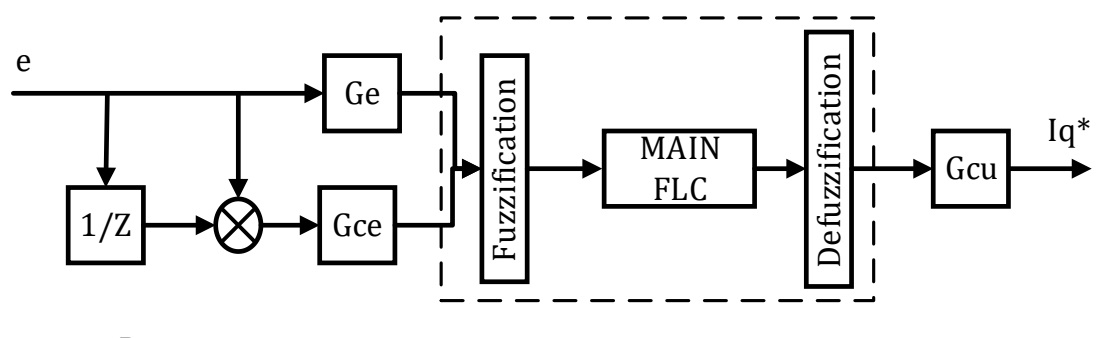

Preprocessing MISO Fuzzy Logic Postprocessing

Figure 2. The internal structure of FLSC

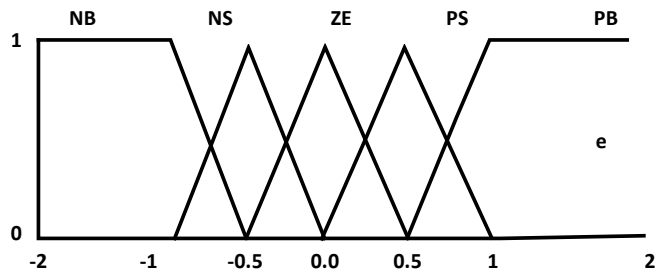

Figure 3. Error membership function

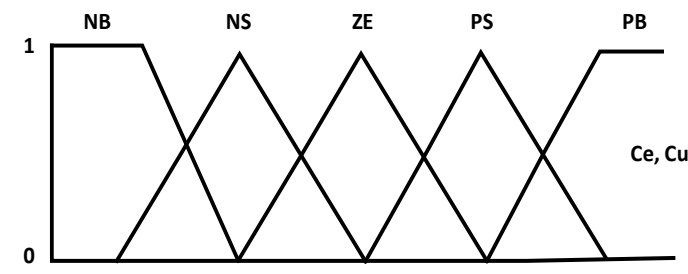

Figure 4. Change of error and output membership function

\subsection{Simplified rules of FLSC}

FLC faced a huge challenge to implement for real-time hardware due to high numbers of fuzzy rules that affect the computational burden [25]. However, the successful operation of FLC is highly dependent on the ability of the fuzzy rules to interact with the properties. Simplified rules are one of the techniques to a realization hardware implementation by reducing the number of rules. Therefore, the computational burden decreased automatically. In this paper, fuzzy rules are simplified based on the dominant rules selection method [24]. Thus, from 25 rules, only 7 rules were given the most significant. The blue box highlight in Table 1 state the number of rules as the result of the simplified selected rules method [24]

\subsection{Proposed ST-MRAC}

The general structure of the MRAC shown in Figure 5 is proposed for a self-tuning mechanism controller consisting of a reference model, an adjustment mechanism, a controller and a plant. Differences were added between the MRAC and the normal control loop model with two additional blocks. First, the reference model is used to provide the idealized response of the adaptive control system to the reference input. Second, the adjustment mechanism is used to modify the parameters of the controller [37]. The error signal from the deviation between model reference output and actual speed is computed in the Auxiliary FLC block. Then, the ouput of this Auxiliary FLC block is fed to the main FLC controller. While Figure 6 shows the overall model of the ST-MRAC controller applied to the IM drive system based on the general structure of the MRAC.

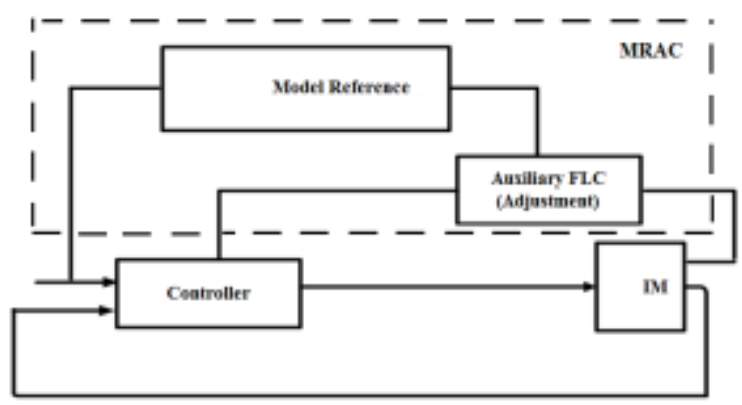

Figure 5. The general structure of MRAC [37] 


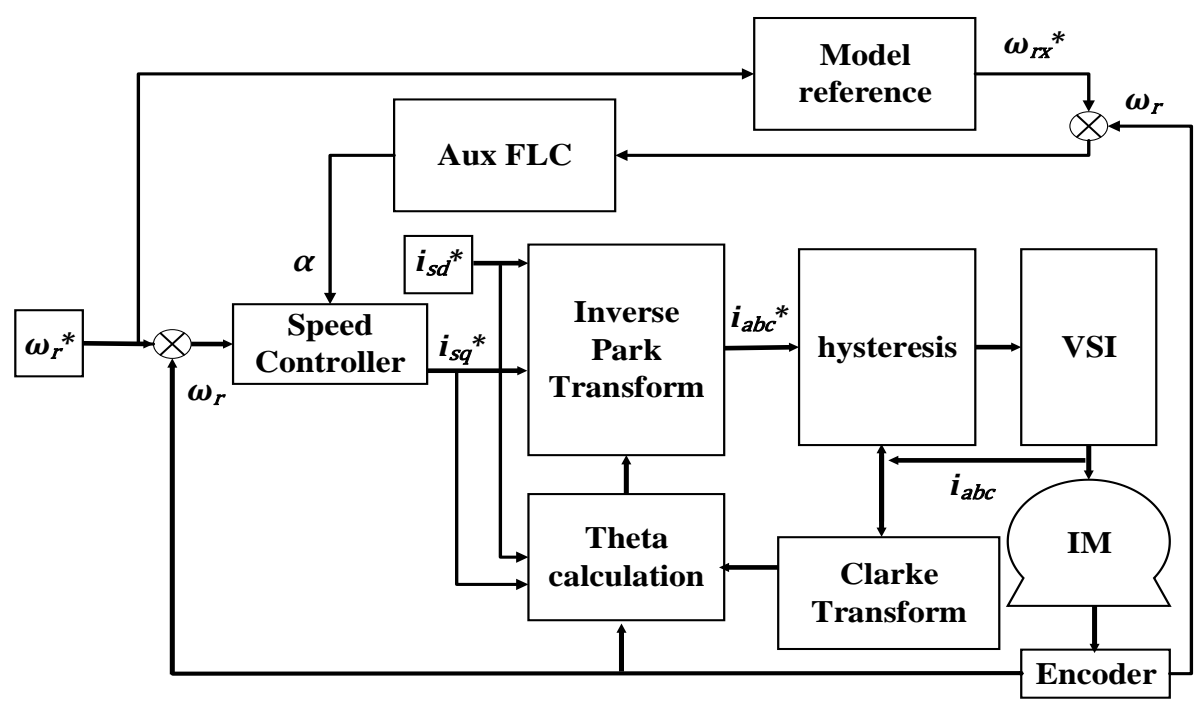

Figure 6. IFOC fed by ST-MRAC

The conceptual of ST-MRAC is tuning FL through MRAC fundamental in order to produce excellent high-performance speed control. The second-order general equation is formulated to be a reference model block and the parameters selected based on the optimum in wide range speed performance. The second order parameters are designed based on the actual motor parameter used than can produce optimum performance. The general equation for the second order system is shown in the following equation [38].

$$
G(s)=\frac{\omega n 2}{s 2+2 \xi \omega n s+\omega n 2}
$$

Where $\omega n, \xi$ is the natural frequency and damping ratio respectively. After the calculation process, the parameter of the reference model is determined as in (4),

$$
G(s)=\frac{1600}{s 2+72 s+1600}
$$

Figure 7 presents the internal structure ST-MRAC, the error between speed demand and reference model will be the input for auxiliary FLC in the adjustment block.

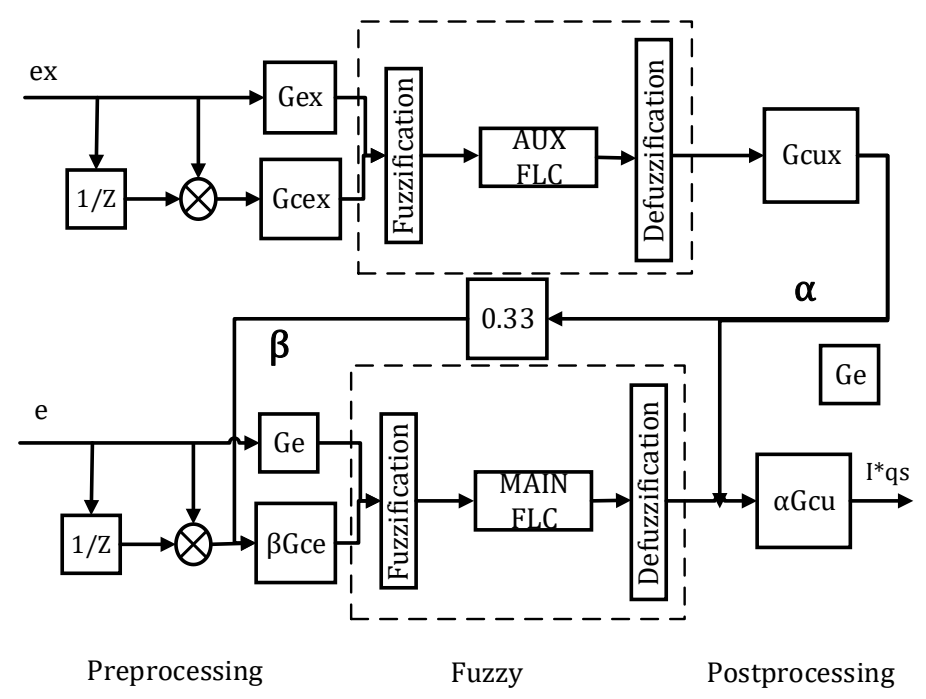

Figure 7. Internal ST-MRAC speed controller 
Here, Multi Inputs Single Output (MISO) type FLC is functions to tune SF gains for the output, $\alpha$ and change of error, $\beta$ scalling factor. The SF gain is continuously tuned based on the input error and change of error. All the scaling factors and membership functions for the main and auxiliary FCL remain unchanged as discussed in the previous part. Only the output, $\alpha$ MF tuned are added for the auxiliary FLC for the tuner, as shown in Figure 8. The overall operation utilized by 14 numbers rule of FLC; 7 rules for main FLC speed controller and 7 rules for auxiliary FLC for tuning SFs as listed below.
a) Rule 1 and 2
: If $\mathrm{E}$ is $\mathrm{NB} / \mathrm{PB}$ and $\mathrm{CE}$ is $\mathrm{ZE}$ then $\alpha$ is $\mathrm{XS} / \mathrm{XL}$
b) Rule 2 and 3
: If $\mathrm{E}$ is NS/PS and CE is ZE then $\alpha$ is $/ \mathrm{L}$
c) Rule 3 and 4
d) Rule 7
: If $\mathrm{E}$ is $\mathrm{ZE}$ and $\mathrm{CE}$ is NS/PS then $\alpha$ is $\mathrm{S} / \mathrm{L}$
: If $\mathrm{E}$ is $\mathrm{ZE}$ and $\mathrm{CE}$ is $\mathrm{M}$ then $\alpha$ is $\mathrm{M}$

The following equation presented the torque current and tuner for the change of error SF. Value of $\beta$ following $\alpha$ coefficient by constant value 0.33 .

$$
\begin{aligned}
& I * q s(n)=i * q s(n-1)+\Delta i * q s(n) * G c u * \alpha \\
& \beta=\alpha * 0.33
\end{aligned}
$$

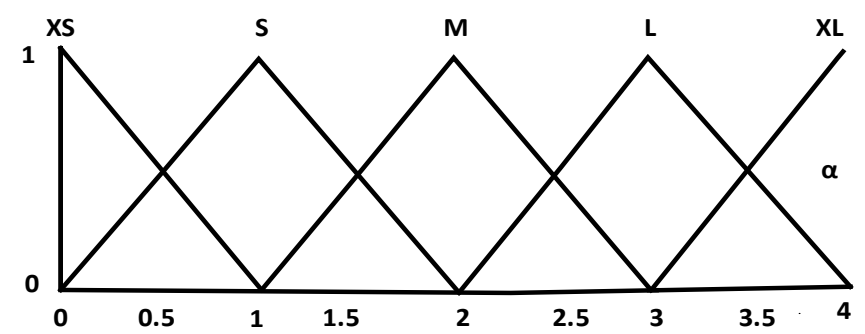

Figure 8. Tuner for Output SF, $\alpha$

\section{DISCUSSION AND RESULTS}

In this section, the performance of each speed controller technique is recorded. The CPFL and STMRAC of the IFOC speed controller model in the Simulink / Matlab software to connect to 3 phase, 4 poles, 2HP IM powered by HCC. To evaluate a comparison of performance between STFL and ST-MRAC in a wide range of low, medium and high-speed operations and load disturbance tested. Details IM as follows rated voltage $=380 \mathrm{~V}$, stator resistance $=3.45 \Omega$, rotor resistance $3.6141 \Omega$, stator inductance $=0.3246 \mathrm{H}$, rotor inductance $=0.3252 \mathrm{H}$, magnetizing inductance $=0.3117 \mathrm{H}$ and inertia $=0.02 \mathrm{kgm} 2$.

\subsection{Simulation results}

Speed performance under no load condition is conducted in both forward and reverse operations. Speed demand is set at $0.5 \mathrm{~s}$ for forward speed operation from the initial standstill condition and then reverses its operation at $4 \mathrm{~s}$. In contrast, load interruption is applied at time $1.5 \mathrm{~s}$ to $3 \mathrm{~s}$ in all low, medium and highspeed range conditions respectively. Figure 9 and Figure 10 captured the simulation performance results. The performance comparisons are made in terms of overshoot or undershoot, rise time, settling time and speed drops. In the analysis, the rise time in speed response was determined to exceed $90 \%$ of speed command in 0\% OS. Table 2 and Table 3 summarized the observation from the simulation speed response. Based on the result, ST-MRAC has shown that it is better to achieve demand for speed in increasing time. ST-MRAC recorded $0.1153 \mathrm{~s}, 0.0892 \mathrm{~s}$ and $0.0646 \mathrm{~s}$ at different speeds, high, medium and low. It takes 0.0196s, 0.0213s and 0.0429s faster than CPFL. While for load interruption, the CPFL recorded average speed drops of $34 \mathrm{rpm}$ lower than the ST-MRAC.

Table 2. Rising time comparison with 0\% OS different speed operation

\begin{tabular}{cccc}
\hline Demand of speed (rpm) & ST-MRAC $(\mathrm{s})$ & CPFL $(\mathrm{s})$ & Different \\
\hline 1400 & 0.1153 & 0.1349 & $0.0196 \mathrm{~s}$ \\
1000 & 0.0892 & 0.1105 & $0.0213 \mathrm{~s}$ \\
600 & 0.0646 & 0.1075 & $0.0429 \mathrm{~s}$ \\
\hline
\end{tabular}




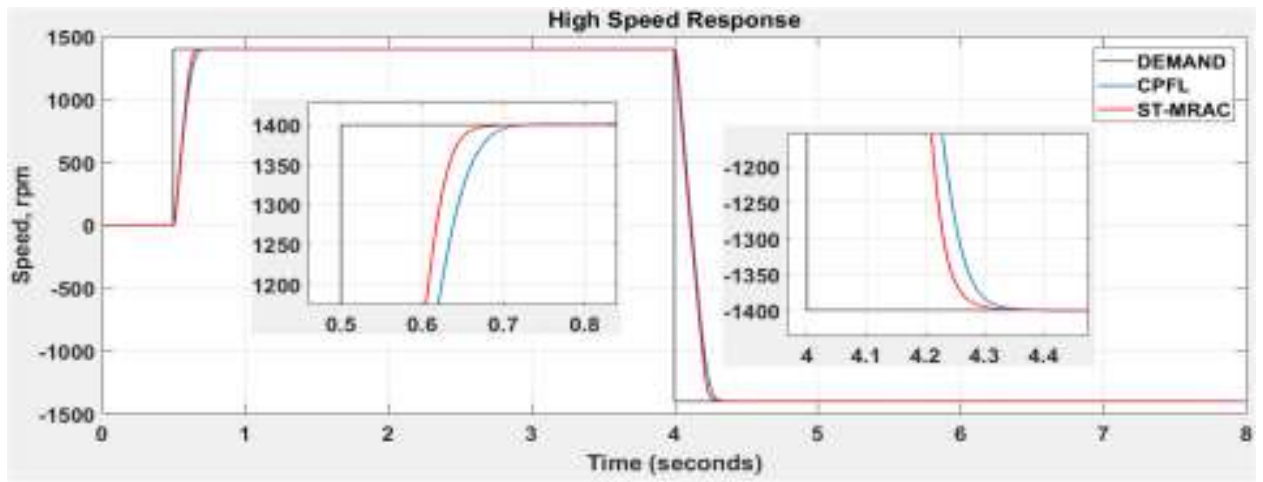

(a)

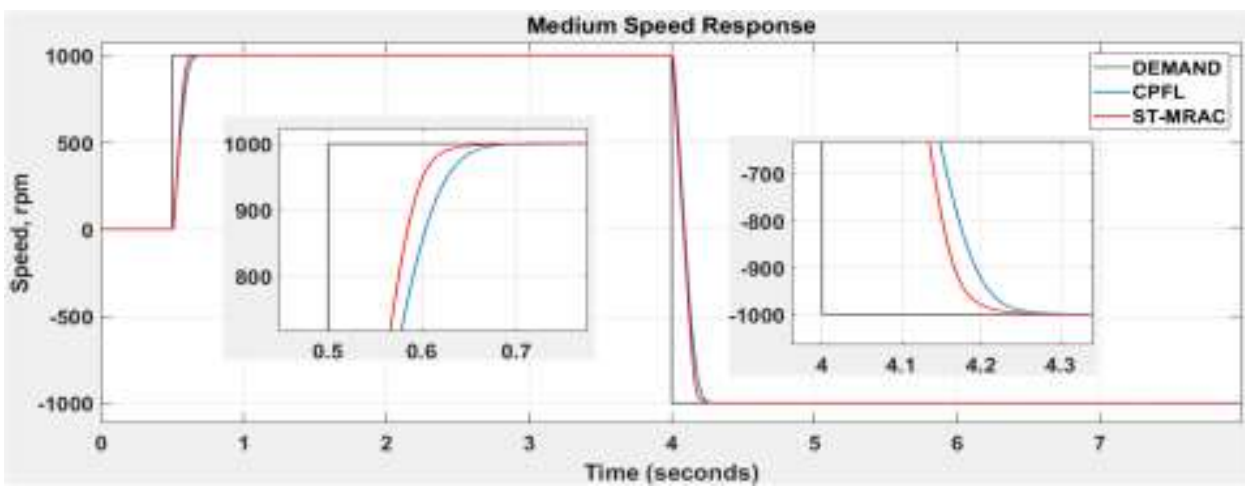

(b)

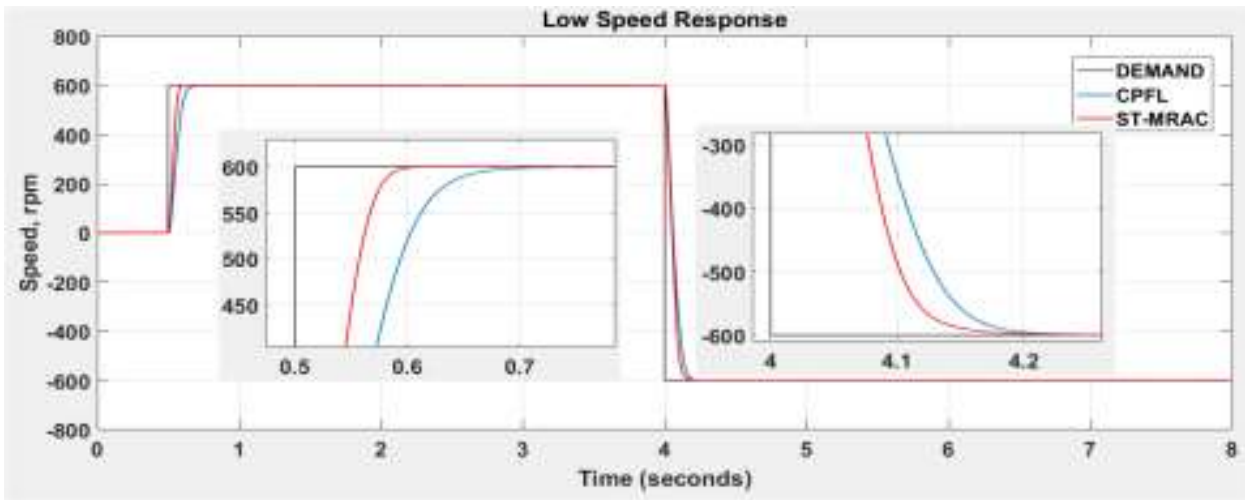

(c)

Figure 9. Speed performance response (a) high speed $1400 \mathrm{rpm}$, (b) medium speed 1000rpm, (c) low speed 600rpm

Table 3. Speed drop when interruption load to the system

\begin{tabular}{ccccccc}
\hline $\begin{array}{l}\text { Demand for } \\
\text { speed (rpm) }\end{array}$ & $\begin{array}{c}\text { ST-MRAC } \\
(\mathrm{rpm})\end{array}$ & $\begin{array}{c}\text { Loaded } \\
\text { CPFL } \\
(\mathrm{rpm})\end{array}$ & $\begin{array}{c}\text { Different } \\
(\mathrm{rpm})\end{array}$ & ST-MRAC (rpm) & $\begin{array}{c}\text { Unloaded } \\
\text { CPFL } \\
(\mathrm{rpm})\end{array}$ & $\begin{array}{c}\text { Different } \\
(\mathrm{rpm})\end{array}$ \\
\hline 1400 & 1362.0 & 1328.0 & 34.0 & 1453.0 & 1477.0 & 24.0 \\
1000 & 963.0 & 929.7 & 33.3 & 1052.0 & 1076.0 & 24.0 \\
600 & 562.4 & 527.5 & 34.9 & 650.9 & 673.2 & 22.3 \\
\hline
\end{tabular}




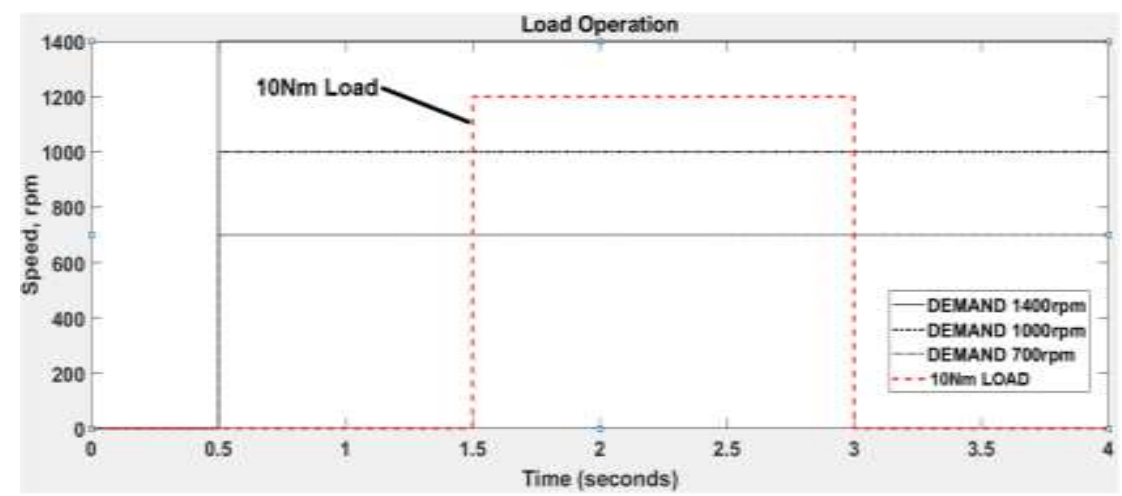

(a)

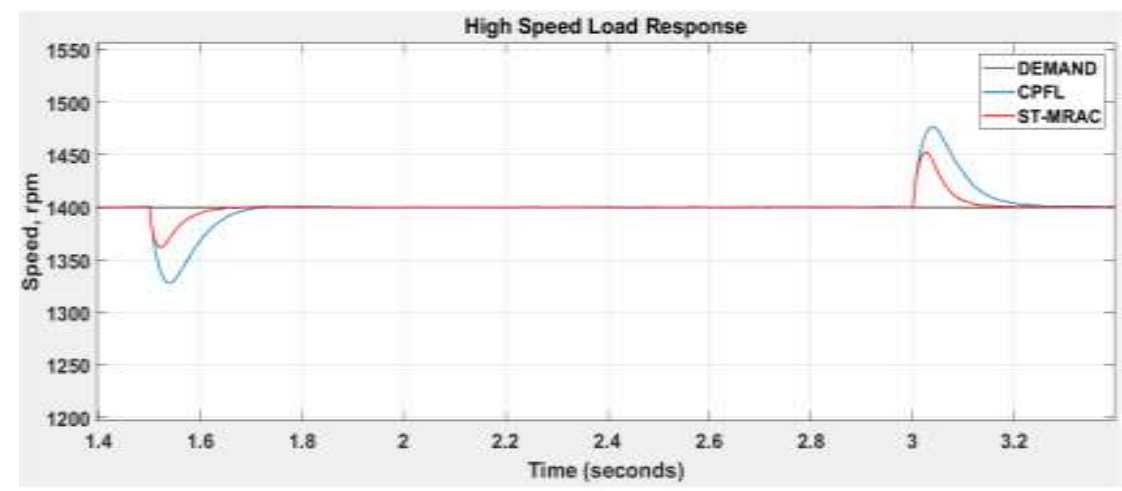

(b)

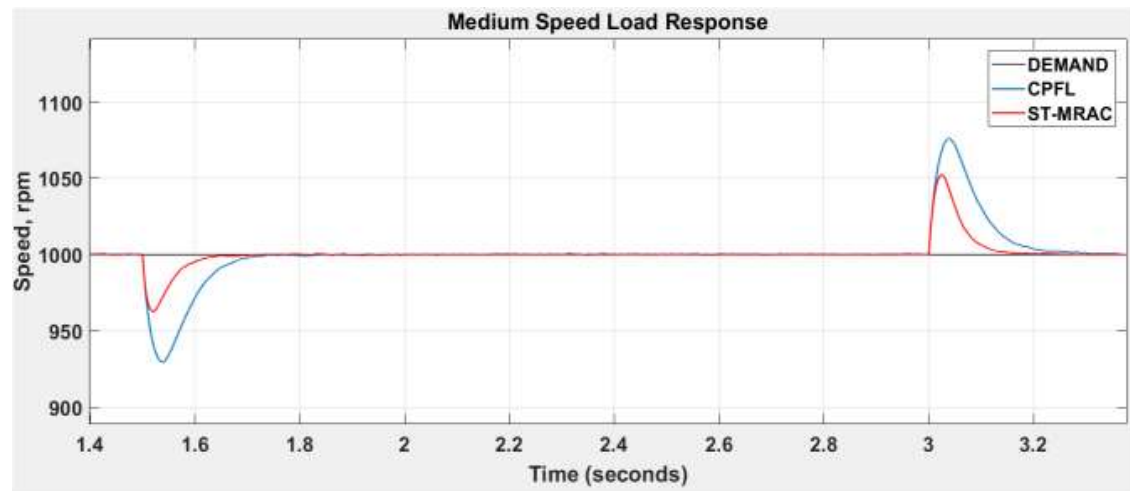

(c)

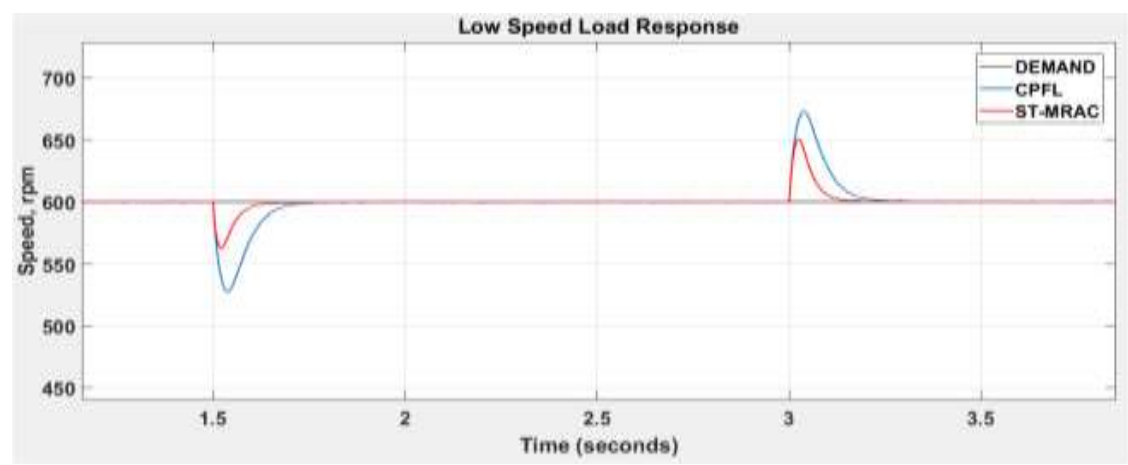

(d)

Figure 10. Speed performance load response (a) flow operation load disturbance (b) high speed $1400 \mathrm{rpm}$, (c) medium speed 1000rpm, (d) low speed 600rpm 


\subsection{Hardware Experimental Results}

The experimental test validated the effectiveness and robustness of the proposed ST-MRAC for IM drive at different operating conditions. The drive has been tested in real-time implementation using MATLAB/Simulink and ControlDesk programs interface with hardware equipment by dSPACE 1103 controller. By interfacing, the closed-loop system can be obtained. The IM, speed sensor, VSI, 3 phase AC power supply, rectifier, gate drivers and current sensor are parts of the hardware for inverter supplied by 537 Vdc. All the testing procedures and parameters of fuzzy such as SF, MF and rules are set as in simulation setup. The hardware speed performance results are shown in Figure 11 and Figure 12 for no load and loaded conditions.

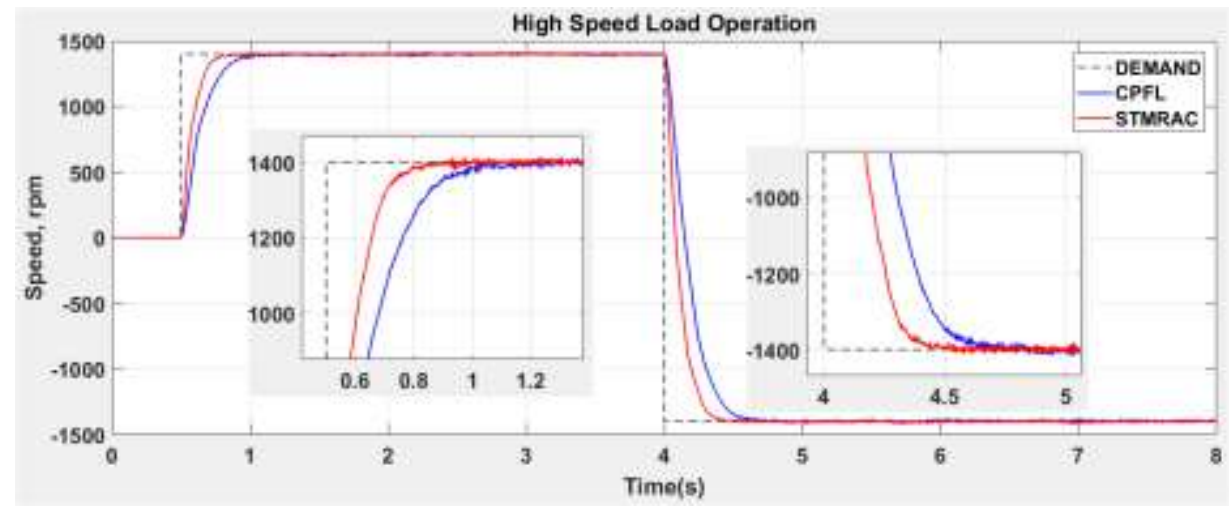

(a)

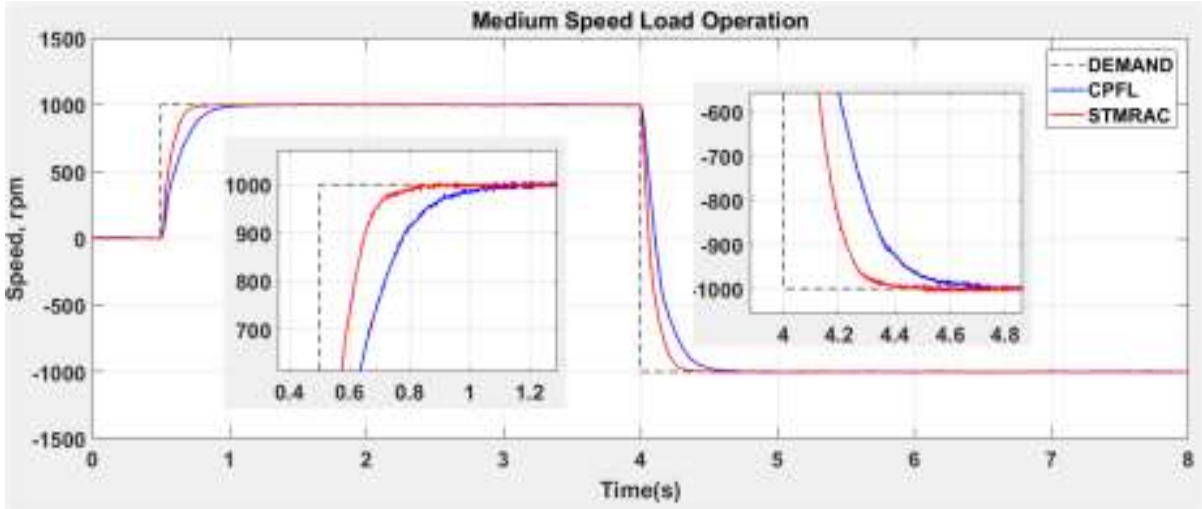

(b)

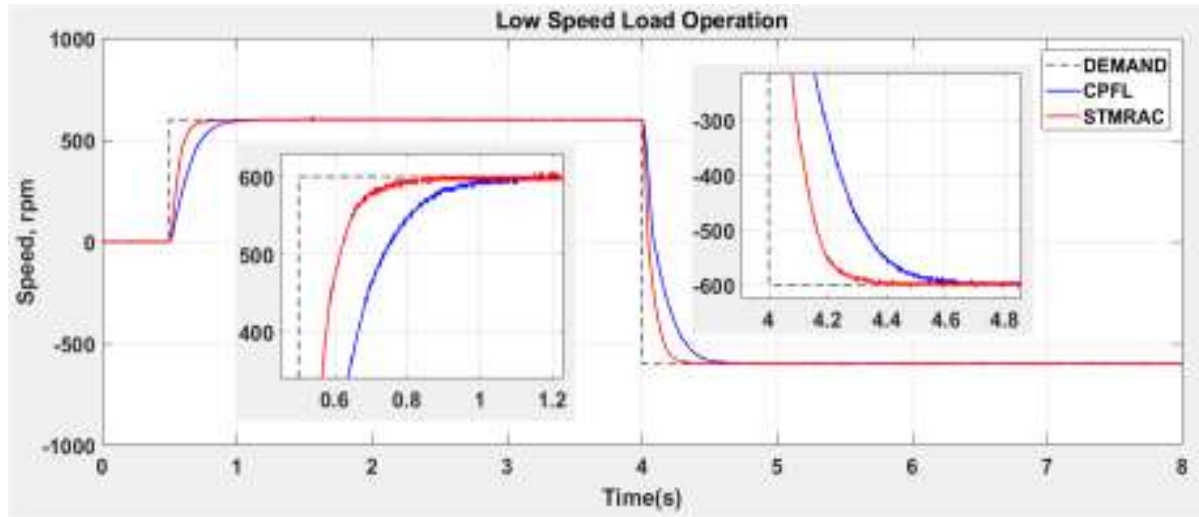

(c)

Figure 11.Speed performance hardware response (a) high speed $1400 \mathrm{rpm}$, (b) medium speed 1000rpm, (c) low speed 600rpm 
Table 4 summarizes the speed performance result. Based on the comparison data, the ST-MRAC gives better speed performance compare to the CPFL in the drive of IM in all test conditions. For forward operation ST-MRAC show 0.1257s, 0.1336s and 0.1472s faster than CPFL in high, medium and low speed operation respectively. It shows the same performance in suddenly changing direction operation from forward to reverse. ST-MRAC recorded $0.141 \mathrm{~s}, 0.138 \mathrm{~s}$ and $0.188 \mathrm{~s}$ faster in high, medium and low speed operation respectively. For load disturbance tests, ST-MRAS showed improvement compared to CPFL 2.07 per cent at high, 1.47 per cent at medium and 4.06 per cent at low speed operation.

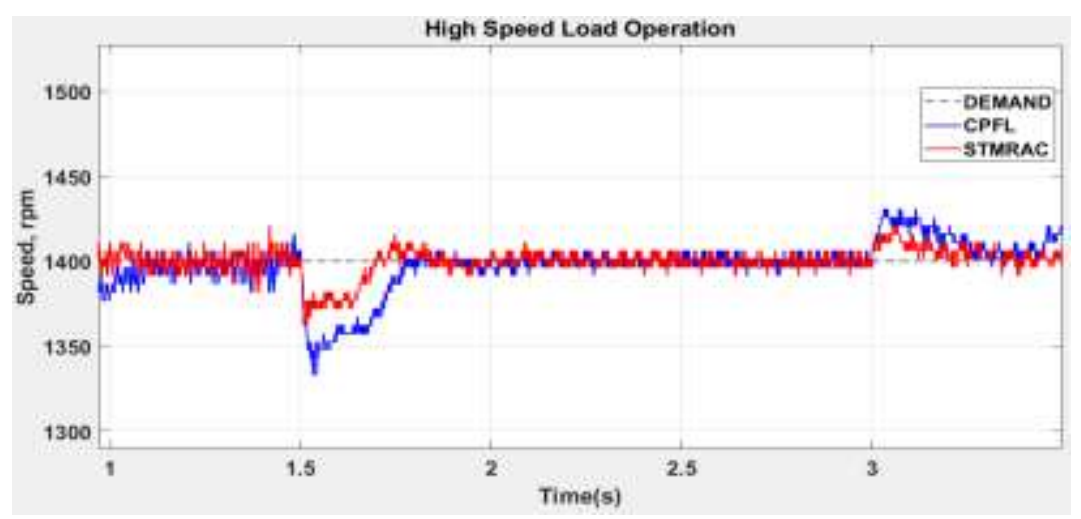

(a)

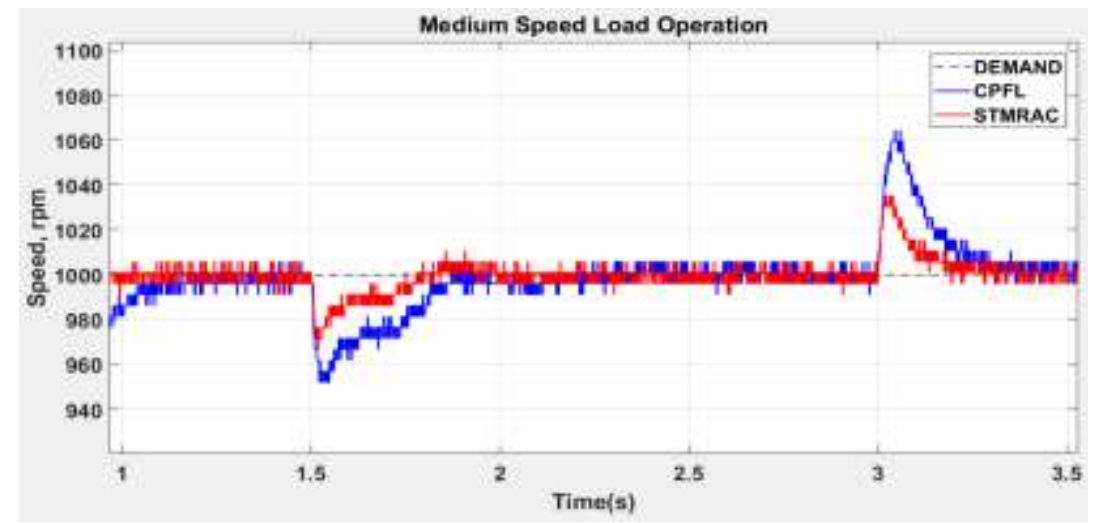

(b)

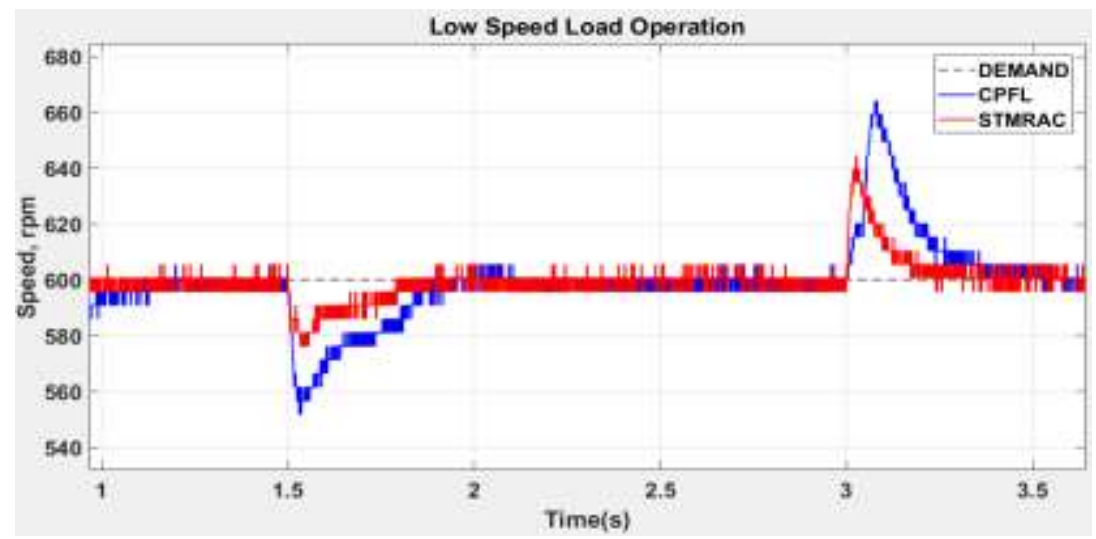

(c)

Figure 12. Speed performance hardware response (a) high speed $1400 \mathrm{rpm}$, (b) medium speed 1000rpm, (c) low speed 600rpm 
Table 4. Summarize experiment speed performance

\begin{tabular}{|c|c|c|c|c|c|c|}
\hline \multirow[b]{2}{*}{ Demand for speed (rpm) } & \multicolumn{3}{|c|}{ ST-MRAC } & \multicolumn{3}{|c|}{ CPFL } \\
\hline & Rise time (s) & load & unload & Rise time (s) & load & unload \\
\hline 1400 Forward & 0.1763 & 1362.0 & 1421.0 & 0.3020 & $1333.0 \mathrm{rpm}$ & $1431.0 \mathrm{rpm}$ \\
\hline 1400 Reverse & 0.2770 & $\mathrm{rpm}$ & $\mathrm{rpm}$ & 0.4180 & & \\
\hline 1000 Forward & 0.1512 & 966.8 & 1035.0 & 0.2848 & $952.1 \mathrm{rpm}$ & $1064.0 \mathrm{rpm}$ \\
\hline 1000 Reverse & 0.2270 & $\mathrm{rpm}$ & $\mathrm{rpm}$ & 0.3650 & & \\
\hline 600 Forward & 0.1405 & 576.2 & 644.5 & 0.2877 & $551.8 \mathrm{rpm}$ & $664.1 \mathrm{rpm}$ \\
\hline 600 Reverse & 0.1880 & $\mathrm{rpm}$ & $\mathrm{rpm}$ & 0.3760 & & \\
\hline
\end{tabular}

\section{CONCLUSION}

In this paper, self tuning fuzzy logic - model reference adaptive speed controller for Induction Motor Drive is proposed. This proposed mechanism is to tuning output scaling factor and change of error scaling factor simultaneously. The dominant rules selection method for simplified rules applied 7 rules of each FLC tuning FLC mechanism to realized real-time implementation. This method proved the robustness of speed performance compare to constant parameter fuzzy logic controller in low, medium and high speed operations based on simulation and hardware.

\section{ACKNOWLEDGEMENT}

The authors would like to acknowledge their gratitude to Electric Vehicle Drive Lab, Faculty of Electrical Engineering, Universiti Teknikal Malaysia Melaka (UTeM) for providing the resources and support in this study.

\section{REFERENCES}

[1] P. J. Shaija and A. E. Daniel, "An Intelligent Speed Controller Design for Indirect Vector Controlled Induction Motor Drive System,” Procedia Technol., vol. 25, no. Raerest, pp. 801-807, 2016.

[2] M. Asad, M. Arif, and U. Khan, "Speed control of Induction Motor via Fuzzy Proportional Integral (FPI) controller," 2016 Int. Conf. Comput. Electron. Electr. Eng. ICE Cube 2016 - Proc., no. 1, pp. 186-189, 2016.

[3] C. M. F. S. Reza, M. D. Islam, and S. Mekhilef, "A review of reliable and energy efficient direct torque controlled induction motor drives," Renew. Sustain. Energy Rev., vol. 37, pp. 919-932, 2014.

[4] G. Yang and T. H. Chin, "Adaptive-Speed Identification Scheme for a Vector-Controlled Speed Sensorless Inverter-Induction Motor Drive," IEEE Transactions on Industry Applications. 1993.

[5] I. Ferdiansyah, E. Purwanto, and N. A. Windarko, "Fuzzy Gain Scheduling of PID (FGS-PID) for Speed Control Three Phase Induction Motor Based on Indirect Field Oriented Control (IFOC)," Emit. Int. J. Eng. Technol., vol. 4, no. 2, pp. 237-258, 2016.

[6] Z. Y. Zhao, M. Tomizuka, and S. Isaka, "Fuzzy Gain Scheduling of PID Controllers," IEEE Trans. Syst. Man Cybern., vol. 23, no. 5, pp. 1392-1398, 1993.

[7] M. N. Uddin, T. S. Radwan, and M. A. Rahman, "Performances of Fuzzy-Logic-Based Indirect Vector Control for Induction Motor Drive,” vol. 38, no. 5, pp. 1219-1225, 2002.

[8] K. Premkumar, T. Thamizhselvan, M. Vishnu Priya, S. B. Ron Carter, and L. P. Sivakumar, "Fuzzy anti-windup pid controlled induction motor," Int. J. Eng. Adv. Technol., vol. 9, no. 1, pp. 184-189, 2019.

[9] F. R. Yaseen and W. H. Nasser, "Design Of Speed Controller For Three Phase Induction Motor Using Fuzzy Logic Approach,” Iraqi J. Comput. Commun. Control Syst. Eng., vol. 18, no. 3, pp. 12-25, 2018.

[10] A. Lokriti, I. Salhi, S. Doubabi, and Y. Zidani, "Induction motor speed drive improvement using fuzzy IP-selftuning controller. A real time implementation," ISA Trans., vol. 52, no. 3, pp. 406-417, 2013.

[11] L. Mokrani and R. Abdessemed, "A fuzzy self-tuning PI controller for speed control of a field oriented induction motor drive," Adv. Model. Anal. C, vol. 60, no. 1-2, pp. 77-86, 2005.

[12] R. K. Mudi and N. R. Pal, “A self-tuning fuzzy pd controller,” IETE J. Res., vol. 44, no. 4-5, pp. 177-189, 1998.

[13] S. C. Wang and Y. H. Liu, "A modified PI-like fuzzy logic controller for switched reluctance motor drives," IEEE Trans. Ind. Electron., vol. 58, no. 5, pp. 1812-1825, 2011.

[14] Y. H. Asgharpour Alamdari H.*, Alinejad Beromi Y., "A Fuzzy-Based Speed Controller for Improvement Of Induction Motor's Drive Performance," vol. 13, no. 2, pp. 61-70, 2016.

[15] H. Erdem and O. T. Altinoz, "Tuning of output scaling factor in PI-like fuzzy controllers for power converters using PSO,” J. Intell. Fuzzy Syst., vol. 30, no. 5, pp. 2677-2688, 2016.

[16] M. H. N. Talib, Z. Ibrahim, Z. Rasin, J. Mat Lazi, and M. Azri, "Investigation of different rules size FLSC performance applied to induction motor drive," J. Telecommun. Electron. Comput. Eng., vol. 9, no. 2-8, pp. 165-169, 2017.

[17] M. Zerikat, A. Mechernene, and S. Chekhroun, "Adaptive vector control of induction motor based on a Fuzzy SelfTuning IP Speed Controller,” 2016 5th Int. Conf. Syst. Control. ICSC 2016, pp. 97-102, 2016.

[18] R. R. De Maity and R. K. Mudi, “A Robust Self-Tuning Fuzzy Controller for Integrating Systems,” pp. 2-7, 2012.

[19] R. Arun Kumar and J. L. Febin Daya, "A novel self - Tuning fuzzy based PID controller for speed control of 
induction motor drive,” 2013 Int. Conf. Control Commun. Comput. ICCC 2013, no. Iccc, pp. 62-67, 2013.

[20] N. Farah et al., "A Novel Self-Tuning Fuzzy Logic Controller Based Induction Motor Drive System: An Experimental Approach," IEEE Access, vol. 7, pp. 68172-68184, 2019.

[21] C. H. Chou and H. C. Lu, "A heuristic self-tuning fuzzy controller," Fuzzy Sets Syst., vol. 61, no. 3, pp. 249-264, Feb. 1994.

[22] M. H. N. Talib, Z. Ibrahim, Z. Rasin, J. M. Lazi, and S. N. M. Isa, "Simplified self-tuning Fuzzy Logic Speed controller for induction motor drive," PECON 2016 - 2016 IEEE 6th Int. Conf. Power Energy, Conf. Proceeding, pp. 188-193, 2017.

[23] Q. A. Tarbosh et al., "Review and Investigation of Simplified Rules Fuzzy Logic Speed Controller of High Performance Induction Motor Drives," IEEE Access, vol. 8, pp. 49377-49394, 2020.

[24] M. H. N. Talib et al., "An improved simplified rules Fuzzy Logic Speed Controller method applied for induction motor drive," ISA Trans., 2020.

[25] N. Farah, M. H. N. Talib, Z. Ibrahim, J. M. Lazi, and M. Azri, "Self-tuning fuzzy logic controller based on takagisugeno applied to induction motor drives," Int. J. Power Electron. Drive Syst., vol. 9, no. 4, pp. 1967-1975, Dec. 2018.

[26] K. Zeb, Z. Ali, K. Saleem, W. Uddin, M. A. Javed, and N. Christofides, "Indirect field-oriented control of induction motor drive based on adaptive fuzzy logic controller," Electr. Eng., vol. 99, no. 3, pp. 803-815, 2017.

[27] L. Gopal, M. M. T. Student, and T. George, "Sliding-Mode And Fuzzy-Logic Adaptation Mechanism For MRAS Sensorless Vector Controlled Induction Motor With Temperature Monitoring." Conference on Emerging Devices and Smart Systems (ICEDSS), 2016.

[28] Z. Boulghasoul, A. Elbacha, E. Elwarraki, and D. Yousfi, "Robustness of fuzzy controller based adaptation mechanism for MRAS sensorless IM drives," in 19th International Conference on Electrical Machines, ICEM, 2010.

[29] Z. Salleh, M. Sulaiman, and R. Omar, "Tuning Fuzzy Membership Functions to Improve Performance of Vector Control Induction Motor Drives, JTEC" vol. 8, no. 2, pp. 1-4, 1843.

[30] A. Fattah, "ScholarWorks at WMU Design and Analysis of Speed Control Using Hybrid PID-Fuzzy Controller for Induction Motors." Western Michigan University, 2015.

[31] Y. Bensalem and M. N. Abdelkrim, "A Sensorless Neural Model Reference Adaptive Control for Induction Motor Drives". 2009 3rd International Conference on Signals, Circuits and Systems (SCS), 2009.

[32] J. Peter, M. S. Kp, R. Lakshmi, and R. Ramchand, "Nearly Constant Switching Space Vector Based Hysteresis Controller for VSI Fed im Drive," IEEE Trans. Ind. Appl., vol. 54, no. 4, pp. 3360-3371, 2018.

[33] N. Farah, M. H. N. Talib, Z. Ibrahim, S. N. M. Isa, and J. M. Lazi, "Variable hysteresis current controller with fuzzy logic controller based induction motor drives,” 2017 7th IEEE Int. Conf. Syst. Eng. Technol. ICSET 2017 Proc., October, pp. 122-127, 2017.

[34] D. A. Linkens and M. F. Abbod, "Self-organising fuzzy logic control and the selection of its scaling factors," Trans. Inst. Meas. Control, vol. 14, no. 3, pp. 114-125, 1992.

[35] H. X. Li and H. B. Gatland, “A New Methodology for Designing a Fuzzy Logic Controller," IEEE Trans. Syst. Man. Cybern., vol. 25, no. 3, pp. 505-512, 1995.

[36] H. X. Li and H. B. Gatland, "Conventional fuzzy control and its enhancement," IEEE Trans. Syst. Man, Cybern. Part B Cybern., vol. 26, no. 5, pp. 791-797, 1996.

[37] P. Jain and N. M.J, "Design of a Model Reference Adaptive Controller Using Modified MIT Rule for a Second Order System," Adv. Electron. Electr. Eng., vol. 3, no. 4, pp. 477-484, 2013.

[38] M. Masiala, B. Vafakhah, J. Salmon, and A. M. Knight, "Fuzzy self-tuning speed control of an indirect fieldoriented control induction motor drive," IEEE Trans. Ind. Appl., 2008. 